\title{
Lack of retardation with convulsed recipients in the kindling paradigm
}

\author{
JOHN GAITO \\ York University, Downsview, Ontario, Canada M3J 1P3
}

\begin{abstract}
Previous experiments indicated that the development of clonic convulsions could be retarded by intraperitoneal injections of brain homogenate supernatant from male Wistar rats which had previously convulsed via amygdaloid electrical stimulation when naive recipients were used. Two further experiments were conducted with recipients which had reached the convulsion stage. In each of these experiments there was no indication of a retardation or suppressive effect.
\end{abstract}

In previous research the kindling paradigm (Goddard, McIntyre, \& Leech, 1969) was used in combination with the "transfer experiment" (Gaito, 1971). These experiments involved the evaluation of the effects of brain homogenate supernatant from kindled (E) and nonkindled (C) rats on the kindling rates of recipients. The results showed that a "retardation effect" was present when rats were injected intraperitoneally (i.p.) with supernatant from kindled rats (Gaito \& Gaito, 1974; Gaito, 1975, 1976). Over all experiments, the mean number of trials to first clonic convulsion (CC) for experimental recipients was 14.3 with 118 rats and for control recipients 10.2 (80 animals). These results indicated a clear retardation effect.

In these experiments all recipients were naive, i.e., had received no brain stimulation. This paper reports the results of two further experiments in which recipients were rats which had reached the clonic convulsion stage.

\section{METHOD}

Experimental and control donor rats (E, C) had bipolar electrodes implanted unilaterally into the amygdala as in previous experiments. (Exact details are provided in Gaito \& Gaito, 1974.) Seven days after surgery, the kindling procedures began. Experimental donor rats (E) were stimulated three times daily (with $1 \mathrm{~h}$ between trials) by a $60-\mathrm{Hz}$ sine wave of $100-\mu \mathrm{A}$ intensity (peak to peak) for $30 \mathrm{sec}$ from a Lafayette sine wave stimulator. A response was scored as a $\mathrm{CC}$ only if the convulsion continued after termination of the current. On the 10 th $C C$ trial, at 10 min after the initiation of the trial, the rats were sacrificed by decapitation. The brain was rapidly removed; the olfactory bulbs, cerebellum, and brain stem parts below the cerebellum were deleted; the remainder was used for injections. Control donors (C) were connected to stimulator lead wires but received no stimulation. The Cs were sacrificed and treated in the same manner as the Es.

The $\mathrm{E}$ brains were homogenized together in physiological saline. A similar procedure was used with C. brains. The homogenates were shaken overnight at $2^{\circ} \mathrm{C}$ and centrifuged at $20,000 \times \mathrm{g}$ for $1 \mathrm{~h}$. The homogenate supernatants from each

Research reported in this paper was supported by the President's NRC Fund (Grant 32) from York University and a grant from the Ontario Society for Crippled Children. of the $\mathrm{E}$ and $\mathrm{C}$ rats were pooled separately and used for injection into $\mathrm{E}$ and $\mathrm{C}$ recipients.

Recipient rats were prepared in the same manner as the donors. Seven days after surgery, amygdaloid stimulation of the $\mathrm{E}$ and $\mathrm{C}$ recipients began. In Experiment $\mathrm{I}$ all recipients were brought to $5 \mathrm{CCs}$, then rested for 15 days. They were injected i.p. with the equivalent of two brain amounts of homogenate supernatant and amygdaloid stimulation began 24 h later.

Nine pairs of rats were used. They were matched into $\mathrm{E}$ and $C$ pairs based on latency and duration of convulsion during the last of the five CC trials. Seven pairs showed a convulsion with $50-\mu \mathrm{A}$ intensity, whereas the other two pairs required $100-\mu \mathrm{A}$ intensity to convulse. Each pair was run for three trials $24 \mathrm{~h}$ after injection for $30-\mathrm{sec}$ duration with the intensity $(50$ or $100 \mu \mathrm{A})$ required for convulsion during the previous five $\mathrm{CC}$ trials.

In Experiment II procedures were similar to those in Experiment I except that three pairs of rats had achieved 5 CCs and three pairs had been brought to $10 \mathrm{CCs}$. Also the intensity was $100 \mu \mathrm{A}$ for 10 -sec duration for all members of the six pairs on the three test trials. The $10-\mathrm{sec}$ duration was slightly greater than the latency of each of the 12 rats during the previous 5 or $10 \mathrm{CC}$ trials.

\section{RESULTS AND DISCUSSION}

In Experiment I all rats achieved a $\mathrm{CC}$ on each of the three trials. Duration and latency were not recorded during these trials.

In Experiment II every rat showed a convulsion on each trial except for one $\mathrm{C}$ rat on the third trial. Such behavior frequently occurs; a rat will show a series of CCs but will occasionally miss a CC and show a behavioral automatism instead. The $\mathrm{C}$ rat was stimulated for one further trial next day and indicated a CC. Duration and latency were recorded in Experiment II. The number of CCs and latency and duration of convulsion (means) for the six pairs in the three tests trials were, respectively: E-3.0, $3.3 \mathrm{sec}, 36.1 \mathrm{sec}$; $\mathrm{C}-2.8$, $4.0 \mathrm{sec}, 34.2 \mathrm{sec}$.

These two experiments seem to suggest that rats which have attained the convulsion stage in the kindling process are not affected by the supernatant from kindled rats. These studies are in sharp contrast to the previous ones which indicated a retardation effect with naive 


\section{GAITO}

recipients. The difference probably is related to the mechanisms underlying the development of the kindled (convulsion) state. Pronounced changes in electrophysiology occur during this development (Gaito, 1974; Goddard, McIntyre, \& Leech, 1969; McIntyre \& Goddard, 1973; Racine, 1972). Thus, it appears that prior to the stabilization of the mechanisms underlying the convulsion state, the supernatant is effective in retarding the development of convulsions. However, as soon as the electrophysiological, and possible neurological, changes are complete enough to bring forth convulsion, the supernatant is no longer effective relative to these convulsions.

\section{REFERENCES}

Garto, J. DNA complex and adaptive behavior. Englewood Cliffs. N.J: Prentice-Hall, 1971.

GaIro, J. The kindling effect. Physiological Psychology, 1974. 2. $45-50$
GaITo, J. Further results obtained with pairing of the "kindling effect" and the "transfer experiment." Physiological Psychology, 1975, 3, 237-239.

Garto. J. Pairing of the transfer experiment with the kindling paradigm: A summary of results. Bulletin of the Psychonomic Society, 1976, 7, 50-52.

GaITo, J.. \& GaITo, S. T. Interanimal negative transfer of the kindling effect. Physiological Psychology, 1974, 2. 379-382.

Goddard, G. V., McInTYRe, D. C., \& LeEch, C. K. A permanent change in brain function resulting from daily electrical stimulation. Experimental Neurology, 1969, 25, 295-330.

MCINTYRE, D. C., \& GODDARD, G. V. Transfer, interference and spontaneous recovery of convulsions kindled from rat amygdala. Electroencephalography and Clinical Neurophysiology, 1973, 35, 533-543.

RACINE, R. J. Modification of seizure activity by electrical stimulation: II. Motor seizure. Electroencephalography and Clinical Neurophysiology, 1972, 32. 281-294.

(Received for publication November 3, 1975.) 